\title{
Evaluating Adoption of Innovations of Mobile Devices and Desktops within Collaborative Environments in a Higher Education Context
}

\author{
Steven Lopes Abrantes ${ }^{1}$ and Luis Borges Gouveia ${ }^{2}$ \\ ${ }^{1}$ Polytechnic Institute of Viseu, Viseu, Portugal \\ ${ }^{2}$ University Fernando Pessoa, Porto, Portugal
}

\begin{abstract}
This study aims to evaluate if students that use laptops or desktops learn when using Google Groups, involving one hundred and twelve students in a higher education context. The research main goal is to validate which of the students, involved in this study, are in the initial and the majority market of adopters and also classify which of them are more in the flow experience. This study is based on the categories proposed by Roger (1995) for the adoption of innovations, and in the flow experience concept, introduced by Csikszentmihalyi (1975). The main purpose of this study is to establish whether the laptops or desktops users in the initial and the majority market of adopters are in the flow experience when using a set of the available Google applications. At the end of the study, it was possible to conclude that students have experienced the flow state and it had a positive effect on their learning experiences both by students using laptops and those, using desktops. For both desktop and laptop users who belong to the initial market, these have a value slightly lower for the flow experience than the users who belong to the majority market. With this we can say that the users that belong to the majority market learn more when using Google Groups than the users that belong to the initial market.
\end{abstract}

Keywords: flow experience; innovation adoption; mobile devices; learning

\section{Introduction}

The use of computers in classrooms brought a significant change to the teaching and learning process, i.e., learning focuses more on the students' needs and knowledge, where teachers act as mentors rather than "talking heads" (a clear allusion to the prevalence of transmitting knowledge) in front of a live audience. This process of teaching and learning promotes an attitude of exploration and discovery and also where the access to education is transcended by the barriers of time and space (Geoghegan, 1994).

The information and communication technologies have already being integrated our current education systems. Some teachers have adopted those technologies in classroom context, modifying the traditional education system, based on a board, chalk and a set of slides. However, there are still teachers who tend to resist to the new information and communication technologies and those may be seen far from widespread use by the academic community.

Despite the potential that the information and communication technologies brought to our today's education, the use of these in schools have been shown as incoherent and in many cases, ineffective (Reinders, 2009).

One reason for this is the challenge for teachers to integrate technology into their classrooms. The use of technology in the classroom requires both pedagogical and

Copyright (C) 2011 Steven Lopes Abrantes and Luis Borges Gouveia. This is an open access article distributed under the Creative Commons Attribution License unported 3.0, which permits unrestricted use, distribution, and reproduction in any medium, provided that original work is properly cited. Contact author: Steven Lopes Abrantes, e-mail: steven@di.estv.ipv.pt 
technical knowledge and therefore a substantial investment of time and resources, both for the institution and for the teacher (Reinders, 2009).

The adoption of technologies for teaching and learning is an innovation that challenges the structure, culture and practice of universities and higher education institutions (Anderson, Varnhagen, \& Campbell, 1998).

The introduction of the information and communication technologies, by some teachers, in a given environment, has a long tradition of being based on knowledge transmission throughout a classroom, which can be seen as a classic case of a diffusion of innovation (Anderson, et al., 1998).

\section{Innovation and Diffusion in Education}

Diffusion is a process by which an innovation is communicated through certain channels over time among members of a social system. Diffusion is a special type of communication in which messages are perceived as new ideas (E. Rogers, 2003).

The decision for an individual about an innovation is not an instantaneous act, but a process that occurs over time and consists of a series of actions (E. Rogers, 2003).

Knowledge occurs when an individual is exposed to the existence of an innovation and gains some understanding of how it works:

- Persuasion occurs when an individual (or other decision making unit) has a favorable or unfavorable attitude towards an innovation;

- Decision occurs when an individual engages in activities that lead to a choice of acceptance or rejection of innovation;

- Implementation occurs when an individual puts an innovation into use;
- Confirmation occurs when an individual seeks to reinforce a decision already made about an innovation, but may reverse its earlier decision if having conflicting messages about the innovation.

In the early days, technology cannot meet all the needs of its users. In the beginning of a technology market lifecycle, the users who use it have a need for technology and they are willing to suffer inconvenience and high costs to obtain them. Over time, the technology matures, offering better performance, lower cost and greater reliability. We can see that, when the technology exceeds the basic needs of most customers, we are at the transition (Norman, 1998).

Users seek efficiency, reliability, low cost and convenience. Besides this, new customers enter the market as the technology matures. In the early stages, the pioneers are willing to invest in new technology because they felt that the benefits exceeded the costs. Customers more conservative wait until the technology proves itself as being a reliable product (Norman, 1998).

The adoption of innovation has been a research subject studied by Everett $M$. Rogers, who identified the individuals in a range from innovators to laggards (E. M. Rogers \& Scott, 1997).

Individuals who adopt an innovation at different points over time, differ from one another in a series of social and psychological characteristics, which is their willingness to accept and adapt to the changes inherent in innovation, and determine the attitude of the next user (Geoghegan, 1994).

\section{Innovators}

The first $2.5 \%$ are called "innovators". Innovators are decided and polite and show a greater propensity to take risks. They appreciate the technology for their own good and are motivated by the idea of 
being an agent of change in their reference group. They are willing to tolerate the initial problems that can accompany the new products or services and are willing to create solutions to these problems.

\section{Early Adopters}

The next $13.5 \%$ of adopters are the "early adopters". They are social leaders and they have a high level of education. They are visionaries in their market and are looking to adopt and use new technologies to achieve a breakthrough that allows them to achieve a competitive advantage in their sector. They are attracted by rewarding and high risk projects. These adopters are not very price sensitive, because they provide competitive gains by adopting new technologies.

\section{Early Majority}

The next $34 \%$ of adopters are formed by the "early majority." They have many social contacts. Instead of looking for revolutionary changes to achieve productivity improvements in their businesses, they are motivated by evolutionary changes. These follow a more thoughtful process; they like innovative products but prefer others to acquire them first.

\section{Late Majority}

The next $34 \%$ are designated by the "late majority". They are skeptical, traditional, and belong to a lower socioeconomic status. They are very price sensitive and require products thoroughly tested. They are motivated to buy technology just to stay at the same level of the competition and often rely on a trusted advisor to help them make sense of technology.

\section{Laggards}

The last $16 \%$ of adopters are made up of "Laggards." Latecomers are skeptical of technology and just want to keep their status. They tend not to believe that technology can improve productivity and are likely to block the purchase of new technologies.
A successful innovation will be adopted by the members of these groups in order, starting with the innovators, followed by early adopters, early majority and the final and perhaps the laggards (Geoghegan, 1994).

Moore (2001) examined the issue of innovation adoption and stated that there is a "break in the normal curve," between the early adopters and the early majority.

Moore (2001) observes that there is a chasm between the innovators and the early adopters who are quick to appreciate the nature and benefits of new products, and the other categories, representing the rest of the adopters, these are people who want the benefits of new technologies, but they do not want to "experience" in all its complicated details. One can consider the transition between these two states difficult to achieve and time consuming.

More than anything else, this problem arises from the significant differences between the early adopters and the early majority (Geoghegan, 1994).

The crossing of the chasm means that when a product has just achieved great success in its initial release, it gains success at the initial market, but for this same product to be carried forward to the rest of the market, it is required an extra effort and a radical transformation (Geoghegan, 1994).

This transition involves the change in the users habits, leading to a replacement of the existing ones (Moore, 2001).

Once the technology reaches maturity, the entire nature of the product changes, and it must be designed, developed and commercialized differently (Norman, 1998).

While the performance, reliability and the cost of technology, is above the needs of customers, the market is dominated by the early adopters: those who need the technology and pay a high price to obtain it. But the vast majority of the customers belong to the early and late majority. These 
last two groups tend to expect that the technology has proven by itself, and insist on a good user experience and also an added value for them (Norman, 1998).

Our emerging markets and developed countries, are demanding more and more new adaptations and new continuous renewals, not only in times of difficulty, but also in order to have success (Moore, 2001).

To be able to cross the chasm, those responsible for the new technologies should listen to the customers and work with them, in order to take care of their concerns (Denning, 2001).

New technologies may never complete the cycle of adaptation of innovation, unless the marketing strategies are identified, in order to make innovations attractive to the early adopters, stabilizing after, for the first two groups of adopters and staying always in the final market (Elgort, 2005). Geoghegan (1994) identifies four factors that make the crossing of the chasm difficult (ignorance of the chasm; the alliance of technologists; separation of end market; and Absence of a compelling reason to adopt):

Ignorance of the Chasm: There is no recognition that the two groups are totally different (initial market and the majority market). A simple explanation of the innovation is not enough for people who belong to the majority market.

The Alliance of Technologists: The problem created by alliances between groups with special interest in educational computing. Geoghegan (1994) identifies three groups that form this alliance: Early adopters and innovative teachers, support staff at the campus and the educational technology providers. Despite the Alliance to foster the development of many educational applications that clearly illustrate the benefits that technology can bring to teaching and learning, they also unwittingly, have worked to prevent the disclosure of these benefits to another population, leading to their exclusion. This
Alliance represents a relatively small group, which may act to exclude the participation of a large number of teachers.

Separation of the End Market: The difference between the visionaries and the early majority is that it can produce situations in which the successes of the early adopters can actually take away the end market. The projects of high visibility in the early market can absorb the initial funds, leaving little or nothing for those with more modest improvements in technology. A good technological application, for example - one that promises a radical improvement in some aspect of the teaching or learning process, which is produced by the visionaries technically comfortable, self-sufficient and with risky experimental conditions, can attract a considerable attention and can be set to the final market, as an excessively high technology in which they are unable to work with it.

\begin{abstract}
Absence of a Compelling Reason to Adopt: The applications are rarely implemented in a way to show their pragmatic value or make clear that the financial benefits clearly outweigh its cost. We must define a technology as an application that performs a task or solves an existing problem markedly better, or that it also allows doing something new in a way that contributes significantly to teaching effectiveness. With the recognition of all the existing factors, which hinder the passage of technological innovations, among the early adopters and early majority, we can also characterize a set of solutions that facilitates the technology to pass the chasm.
\end{abstract}

Also, Geoghegan (1994) identifies four factors that might facilitate the crossing of the abyss (recognition; vertical orientation; convincing value; and Institutional commitment):

Recognition: It must be acknowledged that there is a Chasm and it is also necessary to recognize that the pragmatists are different from enthusiasts. One must recognize their needs and include them in the process. 
Vertical Orientation: Support for the pragmatists should have more emphasis on a support team to guide them better, instead of assistances by enthusiasts. The support team should have experience and credibility on a wide range of areas that combine technical knowledge with a solid understanding of the culture of the disciplines involved.

Convincing Value: Any innovation should demonstrate clearly to the pragmatists, that it can perform an important and existing task in a better way or can perform an inexistent task but important. Side effects and risks of failure should be minimal and they should be very easy to use.

Institutional Commitment: It is debatable whether the institution failed in articulating and acting on a commitment to improve the quality of teaching and learning. It is natural to extend this commitment to the educational technologies, as to improve education. But is how that commitment is articulated in the case of educational applications, which determines whether the users belonging to the final market will be taken by the use of these technologies.

\section{The Flow Experience}

An aspect related with the interaction of the users with collaborative environments has to see with the flow experience introduced by Csikszentmihalyi (Csikszentmihalyi, 1975). The experience of the flow means the sensation that people feel when they are completely involved in what they are doing, that is, people like the experience and want repeat it (Csikszentmihalyi, 1982). This means that for students to be involved with collaborative environments, it is necessary that they presence the flow state.

The theory of the flow allows us to measure the interaction of users with the computer systems, verifying if these are more or less playfulness (Trevino \& Webster, 1992). The flow experience is used in this study to characterize the interaction between the human and the new technologies (Trevino \& Webster, 1992).

When one is in the presence of the flow experience, this will bring to the users, a sense of pleasure of what he is doing. This satisfaction will encourage the user to repeat the task again (Webster, Trevino, \& Ryan, 1993).

Csikszentmihalyi says that a person who is in the presence of the flow state has the following characteristics (Csikszentmihalyi, 1975) and (Csikszentmihalyi, 1990):

- Clear goals and immediate feedback;

- Equilibrium between the level of challenge and personal skill;

- Merging of action and awareness;

- Focused concentration;

- Sense of potential control;

- Loss of self-consciousness;

- Time distortion;

- Autotelic or self-rewarding experience.

For a person to be in the presence of the flow experience, a balance between the level of challenge and personal skill is necessary (Csikszentmihalyi, 1982) .

The sensation of an excellent experience in the accomplishment of any day by day task is our reason of living. If we do not feel this excellent experience with our everyday tasks, we will question our self, if it is worth living (Csikszentmihalyi, 1982).

Previous researches have used the flow experience to measure playfulness, involvement, satisfaction and other states with the involvement in computational environments (Chen, Wigand, \& Nilan, 2000; Ghani \& Deshpande, 1994; Novak \& Hoffman, 1997; Novak, Hoffman, \& Yung, 2000; Trevino \& Webster, 1992).

Trevino and Webster define four dimensions for the flow experience 
(Trevino \& Webster, 1992) which are Control; Attention Focus; Curiosity; and Intrinsic Interest. However, there is one more dimension to consider, sense of time, that is also important to measure the flow state (McKenna \& Lee, 2005) .

Control: Individuals should experience feelings in control within computer interactions (Csikszentmihalyi, 1975).

Attention Focus: Attention focus is another important element of flow. When individuals are in the flow state, their minds are narrowed to what they are doing, filtering out irrelevant thoughts and perceptions (Webster, et al., 1993).

Curiosity: Curiosity is aroused when in the flow state. The curiosity sensation can be aroused through varied, new and admirable stimulations. For example, the new technologies will be able to cause this sensation of curiosity through colors and sounds (Webster, et al., 1993).

Intrinsic Interest: When people feel they are in the flow state, these are involved for the amusement and pleasure (Webster, et al., 1993).

Sense of Time: When people feel they are in the flow state, there is a perceptual transformation of time, characterized by the sensation of time slowing down or speeding up (McKenna \& Lee, 2005).

People who interact with computers, with an entertainment spirit, transmit a much more positive experience, of those, who are in the computer for obligation (Webster, et al., 1993).

\section{Data Analysis}

In order to classify the category of the respondents belonging to the initial market (innovators, early adopters) and the majority market (early majority, late majority and laggards), the scores of individual innovation developed by Anderson, Varnhagen and Campbell (1999) was used. This scoring process was developed based on the assumption that users of the initial market used the technology sooner and gained more experience when compared with the majority market (Anderson, et al., 1998). We used a scale (6 - none to 1 Intensively) for each type of applications used (Google Docs, Google Groups and Facebook), before and after the completion of the project. The result is the sum of the six responses. The minimum value of total responses was 6 , which would classify the most innovative. The maximum total number of answers would be 36 , which would be the classification of the least innovative. The values of innovation for the two devices (laptop and desktop) ranged between 16 and 31, for the case of the desktop the range is between 19 and 30 and for the case of laptops from 16 to 31 .

\section{Initial and Majority Market for the Desktop}

The following figure contains the cumulative frequencies for the case of the desktop, we can see that the first $16 \%$, i.e., the initial market contains five respondents. The next $84 \%$, which are those that belong to the majority market consists of 26 respondents. Those who belong to the latter group are those with the highest values, which mean that they are less innovative than those belonging to the first $16 \%$ of the graph of the cumulative frequencies. 


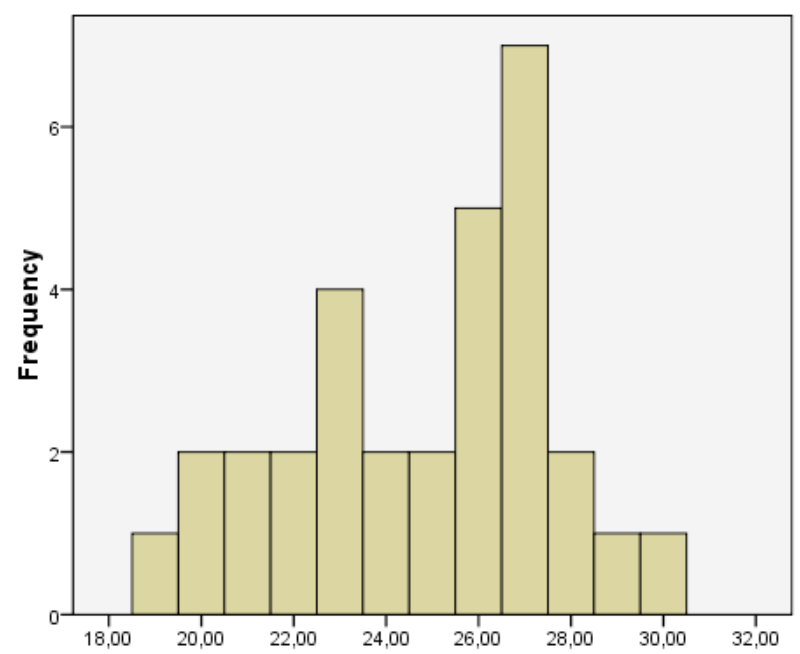

Fig. 1. Cumulative Frequencies (Desktop)

Initial and Majority Market for the Laptop

The following figure, contains the cumulative frequencies for the case of the laptops, we can see that the first $16 \%$, i.e., the initial market contains 14 respondents. The next $84 \%$, which are those that belong to the market majority, consists of 67 respondents. Those who belong to the latter group are those with the highest values, which mean they are less innovative than those belonging to the first $16 \%$ of the graph of cumulative frequencies.

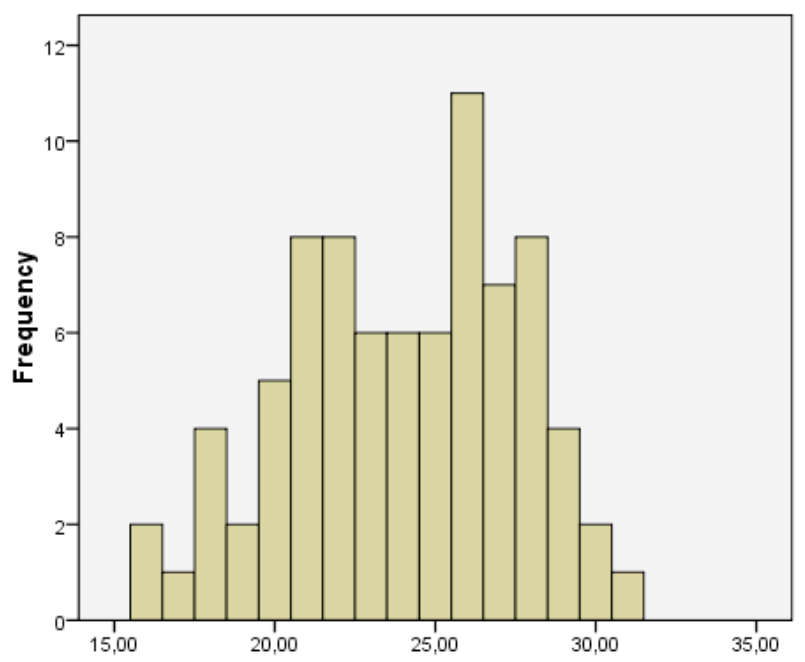

Fig. 2. - Cumulative Frequencies (Laptop)

Initial and Majority Market with the Experience of Flow

Based on the separation of the type of users in terms of innovation, for the case of the laptops and desktop users, we compared, based on the flow experience, which types of users, in terms of innovation, learn more with technology, that is which of them learn more when using Google Groups. 
Table 1 - Flow Experience Values

\begin{tabular}{|l|l|l|l|l|}
\hline & \multicolumn{3}{|l|}{ Desktop } & \multicolumn{2}{l|}{ Laptop } \\
\hline & AI & MM & AI & MM \\
\hline Concentration & 3,0000 & 2,7308 & 3,1786 & 3,3060 \\
\hline Control & 3,1000 & 3,3462 & 3,5714 & 3,9179 \\
\hline Curiosity & 2,9000 & 3,1538 & 3,5357 & 3,5224 \\
\hline $\begin{array}{l}\text { Intrinsic } \\
\text { Interest }\end{array}$ & 2,9000 & 2,8077 & 3,3571 & 3,3806 \\
\hline sense of time & 3,1000 & 2,9808 & 3,1071 & 3,1567 \\
\hline
\end{tabular}

From Table 1 we can infer that for both cases: desktop and laptop, and also for the two groups of innovation (initial and majority market), users are in the presence of the flow experience, i.e., they learn when using Google Groups.

Despite the respondents being in the flow experience for both groups of innovation and for both types of devices, respondents belonging to the initial market have values lower in terms of flow experience than respondents who belong to the majority market.

For the desktop, users who belong to the initial market have a value slightly lower for the flow experience than the users who belong to the majority market. For the case of the laptop, the users associated with the initial market also have lower values of the respondents in the majority market.

\section{Conclusions}

In order to classify our population for the case of respondents who used laptops and for those that used the desktop, scores for the individual innovation developed by Anderson, Varnhagen and Campbell, 1999 were prepared. This score verified that the users who utilized the laptop had a set of scores that were in a range between 16 and 31 values and for the case of the users of a desktop, the range was between 19 to 30 values. These intervals can conclude that users of the laptops had lower scores than those using the desktop; we can infer that the users of laptops are more innovative than the desktop.
Regarding the number of respondents in both groups of innovation (initial and majority market), users of the desktop, contain five respondents associated with the initial market and 26 respondents on the majority market. For the case of laptop users, the initial market contains 14 respondents while the majority market contains 67 respondents.

For both desktop and laptop users who belong to the initial market, these have a value slightly lower for the flow experience than the users who belong to the majority market. With this we can say that the users that belong to the majority market learn more when using Google Groups than the users that belong to the initial market. We can also say, because of the higher values that the laptop users have, that these users learn more, when using Google Groups, than the desktop users.

The research conducted can be further enhanced with more data and further services in order to deepen the promising findings already achieved, comparing mobile devices and desktop use, within higher education institutions. This can provide further insight on how mobile devices can be used to enhance and empower learning initiatives for getting more users to become power users.

\section{References}

Anderson, T., Varnhagen, S., \& Campbell, K. (1998). 'Faculty adoption of teaching and learning technologies: Contrasting earlier adopters and mainstream faculty'. 
Canadian Journal of Higher Education, 28(2,3), 71-98.

Chen, H., Wigand, R. T., \& Nilan, M. (2000). 'Exploring Web users' optimal flow experiences'. Information Technology \& People, 12(4).

Csikszentmihalyi, M. (1975). Beyond Boredom and anxiety. San Francisco, CA.

Csikszentmihalyi, M. (1982, 1982). Towards a Psychology of Optimal Experience. Paper presented at the Annual Review of Personality and Social Psychology.

Csikszentmihalyi, M. (1990). The psychology of optimal experience: Harper Collins.

Denning, P. J. (2001). 'The profession of IT: crossing the chasm'. Commun. ACM, 44(4), 21-25.

Elgort, I. (2005). 'E-learning adoption: Bridging the chasm'.

Geoghegan, W. (1994). 'Whatever Happened to Instructional Technology?' Paper presented at the 22nd Annual Conference of the International Business Schools Computing Association.

Ghani, J., \& Deshpande, S. (1994). 'Task Characteristics and the Experience of Optimal Flow in Human-Computer Interaction'. The Journal of Psychology, 128(4), 381-391.

McKenna, K., \& Lee, S. (2005). A Love Affair with MUDs: Flow and Social Interaction in Multi-UserDungeons. Retrieved $2007 / 10 / 10 /$
Moore, G. A. (2001). Crossing the chasm: Marketing and selling technology products to mainstream customers. New York.: NY: Harper Business.

Norman, D. A. (1998). The invisible computer : why good products can fail, the personal computer is so complex, and information appliances are the solution. Cambridge, Mass: MIT Press.

Novak, T. P., \& Hoffman, D. L. (1997). Measuring the Flow Experience Among Web Users: Vanderbilt University.

Novak, T. P., Hoffman, D. L., \& Yung, Y. (2000). 'Measuring the Customer Experience in Online Environments: A Structural Modeling Approach'. Marketing Science, 19(1), 22-42.

Reinders, H. (2009). Teaching (with) technology. The scope and practice of teacher education for technology. Prospect. Prospect Journal, 24(3), 15-23.

Rogers, E. (2003). Diffusion of Innovations (3 ed.). New York: Free Press.

Rogers, E. M., \& Scott, K. L. (1997). 'The diffusion of innovations model and outreach from the National Network of Libraries of Medicine to Native American Communities'. Draft paper prepared for the National Network of Libraries of Medicine, Pacific Northwest Region, Seattle, WA.

Trevino, L. K., \& Webster, J. (1992). 'Flow in computer-mediated communication'. Communication Research, 19(5), 539-573.

Webster, J., Trevino, L. K., \& Ryan, L. (1993). The dimensionality and correlates of flow in human-computer interaction. computer game research, 9, 411-426. 